\title{
Ex Vivo Characterization of the Action of Sideritis Extract Using Electrical Activity in the Rat Hippocampus Slice Preparation
}

\author{
Wilfried Dimpfel ${ }^{1}$, Leonie Schombert ${ }^{2}$, Björn Feistel ${ }^{3}$ \\ ${ }^{1}$ Justus-Liebig-University Giessen c/o NeuroCode AG, Wetzlar, Germany \\ ${ }^{2}$ NeuroCode AG, Wetzlar, Germany \\ ${ }^{3}$ Finzelberg GmbH \& Co. KG, Andernach, Germany \\ Email: dimpfel1945@web.de, info@neurocode-ag.com, bjoern.feistel@finzelberg.de
}

How to cite this paper: Dimpfel, W., Schombert, L. and Feistel, B. (2016) Ex Vivo Characterization of the Action of Sideritis Extract Using Electrical Activity in the Rat Hippocampus Slice Preparation. Pharmacology \& Pharmacy, 7, 407-416. http://dx.doi.org/10.4236/pp.2016.710048

Received: September 13, 2016

Accepted: October 24, 2016

Published: October 27, 2016

Copyright $\odot 2016$ by authors and Scientific Research Publishing Inc. This work is licensed under the Creative Commons Attribution International License (CC BY 4.0).

http://creativecommons.org/licenses/by/4.0/ (c) (i) Open Access

\begin{abstract}
A hydroethanolic extract $(20 \% \mathrm{~V} / \mathrm{V})$ from Herba Sideritis scardica has been recognized to positively influence cognition. The present investigation aimed at the question if this extract would be able to modify intra-hippocampal communication after oral administration of $100 \mathrm{mg} / \mathrm{kg}$ daily for one week. The glutamatergic synapse between Schaffer Collaterals and pyramidal cells can be tested by electric stimulation using single pulses or theta burst stimulation. The resulting population spike is modulated by compounds acting at the central nervous system or other preparations directly or as ex vivo approach. In this case the effect of the special extract was tested in vitro the next day after repetitive in vivo administration. Conventional recording technique in the in vitro hippocampus slice revealed an increase of the population spike in the presence of single stimuli and theta burst stimuli resulting in increased long-term potentiation. This effect was tried to modulate by several glutamate receptor antagonists, among them compounds targeting at the ionic NMDA receptor (CGS19755), AMPA receptor (NBQX), Kainate receptor (UBP301) and targeting at three metabotropic glutamate receptors (mGluR I (YM298198), mGluRII ((RS)APICA)) and mGluRIII (MSOP). Only NBQX was able to prevent the action of the Sideritis scardica extract. Since the AMPA receptor has been related to cognition in several reports in the literature, it is concluded from this result that the positive action of Sideritis scardica extract on brain function involves a modulation of AMPA receptor dependent neurotransmission.
\end{abstract}

\section{Keywords}

Hippocampus Slice, AMPA Receptor, Sideritis scardica, Greak Mountain Tea, Long Term Potentiation, Hippocampus 


\section{Introduction}

The hippocampal slice preparation is a validated model for direct analysis of interaction of substances with living neuronal tissue [1]. Due to the preservation of the three dimensional structure of the hippocampal tissue, substance effects on the excitability of pyramidal cells can be studied in a unique manner. The stimulation of Schaffer Collaterals leads to release of glutamate resulting in excitation of the postsynaptic pyramidal cells. The result of the electrical stimulation can be recorded as so-called population spike (pop-spike). The amplitude of the resulting population spike represents the number of recruited pyramidal cells. The advantage of the model not only consists in the possibility of recording in vitro during 8 hours but also to modify the excitability of the system in order to create pathophysiological conditions. The model of hippocampal pyramidal cell activity reflects the effects of therapeutic interventions by increase or decrease of the amplitude of the population spike. It therefore provides an excellent model to characterize the action of a new therapeutic principle with respect to changes of brain function under strictly controlled laboratory conditions.

However, this model can also be used under so-called ex vivo conditions. In this case, the drug is administered daily for a week and the hippocampus is taken out the next day for in vitro characterization of the sensitivity of the intra-hippocampal pathway to electric stimulation. If the repetitive administration has succeeded in changing the communication structure within the hippocampus either higher or lower amplitudes of the responses as so-called population spikes can be recorded. Within a second step the mechanism of action of the drug under investigation can be approached by testing several modulators of neurotransmission with respect to their ability to change neuronal transmission in an agonistic or antagonistic manner depending on the effect of the drug. In case of an increase of the population spike amplitude antagonistic chemicals at different glutamate receptors are used in order to see if they still are able to exert their action, in this case decrease of the population spike under the condition of single stimulation or theta burst stimulation.

If a selective antagonist acting at a particular glutamate receptor like the NMDA, a-amino-3-hydroxy-5-methyl-4-isoxazolepropionic acid (AMPA), Kainic acid or any of the metabotropic receptors fails to exert its usual action this is interpreted as consequence of the repetitive drug effects and gives a hint on the mechanism of action of the drug under investigation. The present investigation aimed at the characterisation of the effect of an herbal extract obtained from Sideritis scardica with respect to its effectiveness after repetitive administration (part I of the study) and sensitivity to functional glutamatergic receptor modulation (part II of the study). The extract was administered daily for one week before the hippocampus was taken out for detailed analysis.

\section{Material and Methods}

Hippocampus slices were obtained from 14 (6 for part I and 8 for part II) adult male Sprague Dawleyrats (Charles River Wiga, Sulzbach, Germany). The methodology used was identical to that published earlier [2]. Rats were kept under a reversed day/night 
cycle for 2 weeks prior start of the experiments to allow recording of in vitro activity from slices during the active phase of their circadian rhythm [3]. All slices were preincubated for at least $1 \mathrm{~h}$ in Carbogen saturated ACSF ( $\mathrm{pH}$ 7.4) in a pre-chamber before use [4].

During the experiment the slices were held and treated in a special submersion type chamber (List Electronics, Darmstadt, Germany) according to Haas [5] at $35^{\circ} \mathrm{C}$ [6]. Four slices were used per day from 6 rats taken one day after the daily administration of Sideritis scardica extract or Glucose 1\% for one week. Extr. Sideritisscard. e herb. spir. sicc (item no.: 0232300, Lot no. 15010107) was provided by Finzelberg GmbH \& Co. KG, Andernach, Germany.

In part II of the experimental series slices from 8 rats exposed in vivo to placebo (2) or Sideritis scardica extract (6) were tested in vitro against sensitivity of one of the chemicals acting specifically at glutamatergic receptors as listed in Table 1.

\section{Results}

This experimental series consisted of two parts. In the first part it was tested, if Sideritis extract was able to modulate the hippocampal excitability after dosing it repetitively for one week before the hippocampus was taken out on the next day. During the second part of the investigation it was tried to reverse the modulation by 6 different receptor antagonists interacting with glutamatergic transmission (the transmitter used at the synapse between Schaffer collaterals and hippocampal pyramidal cells is glutamate). Example for responses (population spikes) to single stimuli (SS) or theta burst stimulation (TBS) are documented in Figure 1 for a single slice under placebo conditions and in a Sideritis treated slice ( $100 \mathrm{mg} / \mathrm{kg}$ a day for one week). Amplitude of the population spike of the next day after end of treatment is given as voltage in millivolt.

\subsection{Population Spike Amplitude in the Presence of Placebo or Sideritis}

Daily repetitive administration of $100 \mathrm{mg} / \mathrm{kg}$ of Sideritis extract for one week led to profound increases of the population spike amplitude in comparison to Placebo during

Table 1. Chemicals with selective receptor activity at the glutamatergic system as used in this experimental series. All chemicals were from Bio Trend Chemicals AG, 8602 Wangen/Zürich, Switzerland.

\begin{tabular}{|c|c|c|c|}
\hline CGS 19755 & Cic-4 [Phosphomethyl]-piperdine-2-carboxylic acid & Batch no.: $1 \mathrm{~A} / 33087$ & $\begin{array}{l}\text { NMDA } \\
\text { receptorantagonist }\end{array}$ \\
\hline NBQX & $\begin{array}{l}\text { 2, 3-Dioxo-6-nitro-1, 2, 3, 4-tetrahydrobenzo } \\
\text { [f] quinoxaline-7-sulfonamide disodiumsalt }\end{array}$ & Batch no.: 0608BN/02 & $\begin{array}{l}\text { AMPA } \\
\text { receptorantagonist }\end{array}$ \\
\hline UBP301 & $\begin{array}{l}\text { (S)--Amino-3-[\{4-carboxyphenyl) methyl]-3, 4-dihydro-5-iodo-2, } \\
\text { 4-dioxol (2H)-pyrimidinepropanoicacid }\end{array}$ & Batch no.: 0532BN/01 & $\begin{array}{l}\text { Kainate } \\
\text { receptorantagonist }\end{array}$ \\
\hline YM298198 & $\begin{array}{l}\text { 6-Amino-N-cyclohexyl-3-methyl-thiazolo [3, 2-] } \\
\text { benzimidazole-2-carboxamide hydrochloride }\end{array}$ & Batch no.: 0553BN/01 & MetabotropmGluI \\
\hline RS-APICA & (RS)-1-Amino-5-phosphonoindan-1-carboxylic acud & Batch no.: 0092BN/01 & MetabotropmGluII \\
\hline MSOP & (RS)--Methylserine-O-phosphate & Batch no.: 0349BN/01 & MetabotropmGluII \\
\hline
\end{tabular}




\section{Placebo}

SS<smiles>CCC1CC1C</smiles>

Sideritis

SS

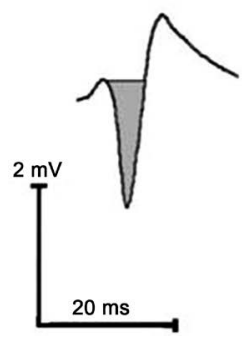

SS

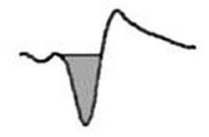

SS

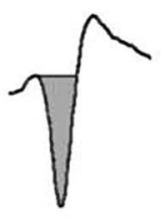

TBS

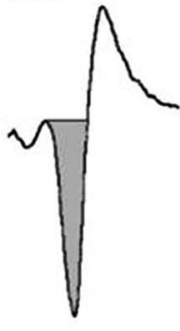

TBS

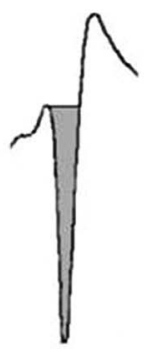

Figure 1. Documentation of original signals (one slice) showing the effects of using single stimuli (SS) or theta burst stimulation (TBS) in the presence of artificial cerebrospinal fluid (ASCF), Glucose 1\% - 1 $\mathrm{ml} / \mathrm{kg}$ and Sideritis scardica extract $100 \mathrm{mg} / \mathrm{kg}$ (administered for 1 week orally by gavage). The amplitude is calculated from baseline to the down reflection of the signal (shadowed). Scales: Time is given in milliseconds (ms), amplitude in millivolts $(\mathrm{mV})$.

single shock stimulation (SS) as well as during theta burst stimulation (TBS). Data are documented in Figure 2 for both recording conditions as time line. The prolonged period during single shock stimulation was chosen in order to be able to follow a possible antagonistic action of glutamate receptor antagonists from 50 to 80 minutes. The difference between the changes of excitability after administration of Sideritis scardica extract in comparison to placebo was highly statistically significant at all measurements. Last three measurements of each period $\left(2^{\text {nd }}-4^{\text {th }}\right)$ were averaged to give one value as documented in Figure 3.

\subsection{Population Spike Amplitude in the Presence of Glutamate Antagonists}

After successful repetitive dosing of $100 \mathrm{mg} / \mathrm{kg}$ of Sideritis scardica extract for one week in comparison to placebo, the question arose, if modulation of the hippocampal excitability was due to changes of the glutamatergic transmission by the extract. In order to find out about this feature 8 more animals ( 2 placebo and 6 Sideritis) were included to solve this question. Regarding the effects of single stimuli the results of the first part of the study were reproduced as documented in Figure 4. Sideritis extract increased population spike amplitude to a considerable and statistically significant degree in a 


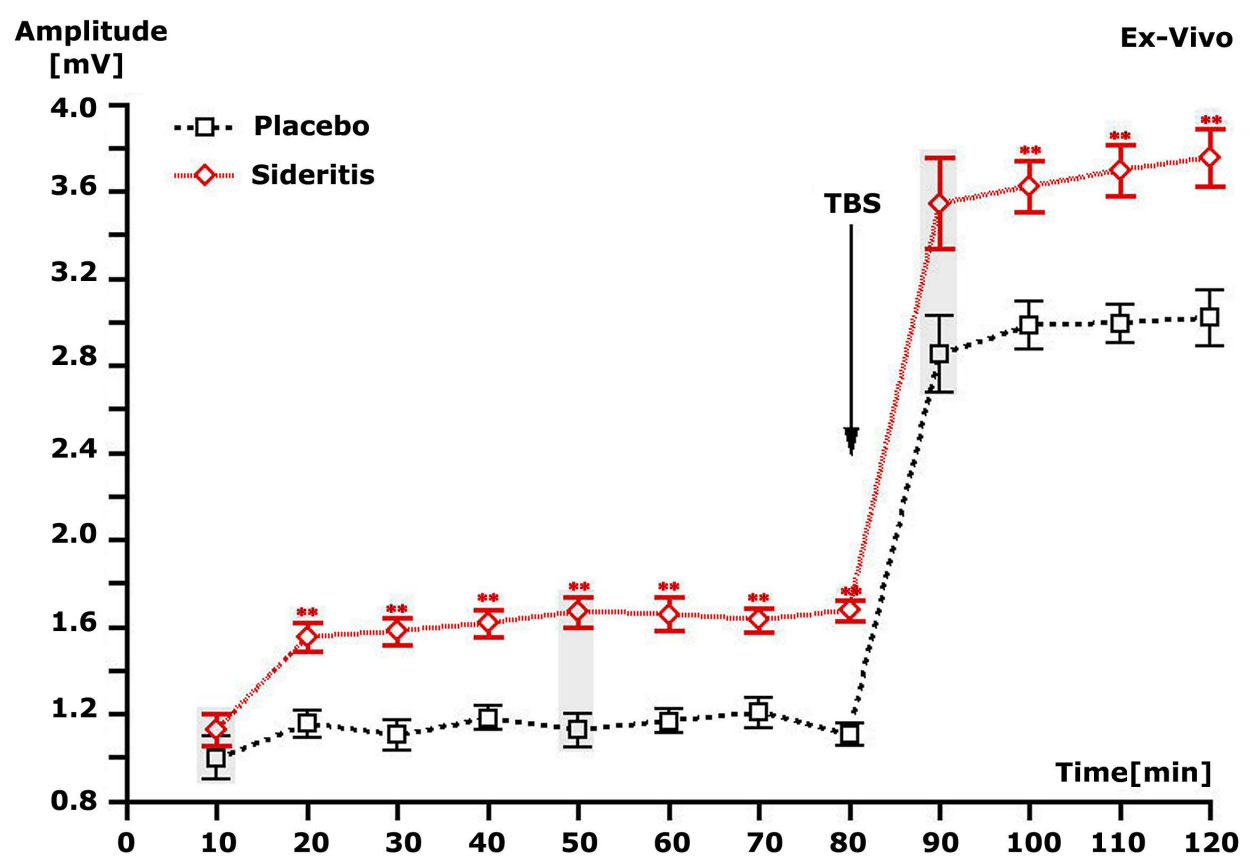

Figure 2. Effects of placebo (glucose $1 \% 1 \mathrm{ml} / \mathrm{kg}$ ) and Sideritis scardica extract $(100 \mathrm{mg} / \mathrm{kg}$ ) on pyramidal cell activity in terms of changes of population spike amplitudes (as voltage on the ordinate). Results as obtained after single stimuli (10 - $80 \mathrm{~min}$ ) or after burst stimuli (90 - $120 \mathrm{~min}$ ). Data are given as mean \pm S.E.M. of $\mathrm{n}=12$ slices from 3 animals/group (given as $\mathrm{mV}$ on the ordinate). The shadowed areas are transitional data, which are not used for average values. Statistics: Wilcoxon u-test Mann und Whitney ${ }^{\star} \mathrm{p}<0.05$; ${ }^{* *} \mathrm{p}<0.01$.

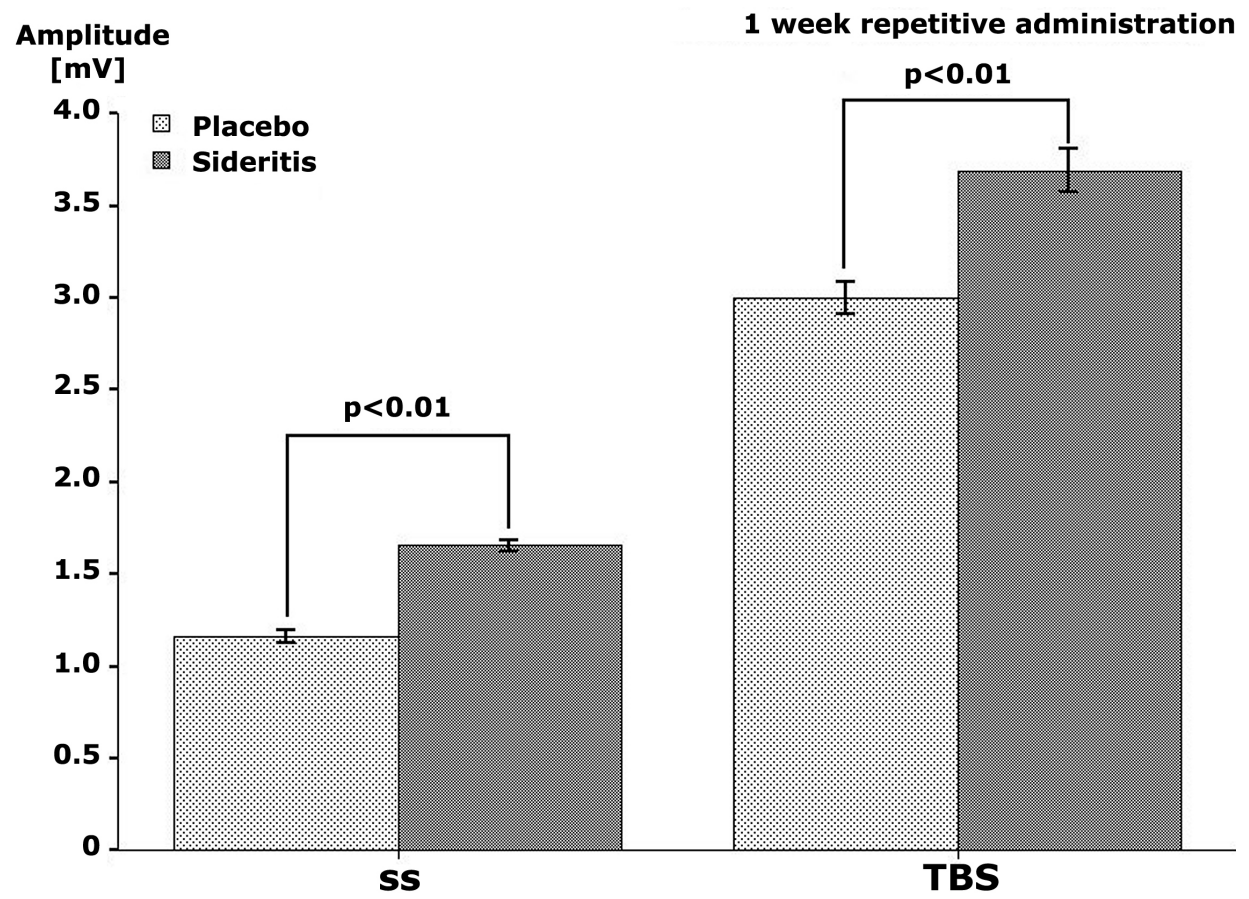

Figure 3. Amplitudes of population spikes (given as $\mathrm{mV}$ on the ordinate) reflecting statistically significant higher excitability after daily repetitive administration of Sideritis scardica extract in comparison to placebo. Data are given as mean \pm S.E.M. of $\mathrm{n}=12$ slices from 3 animals/group. 


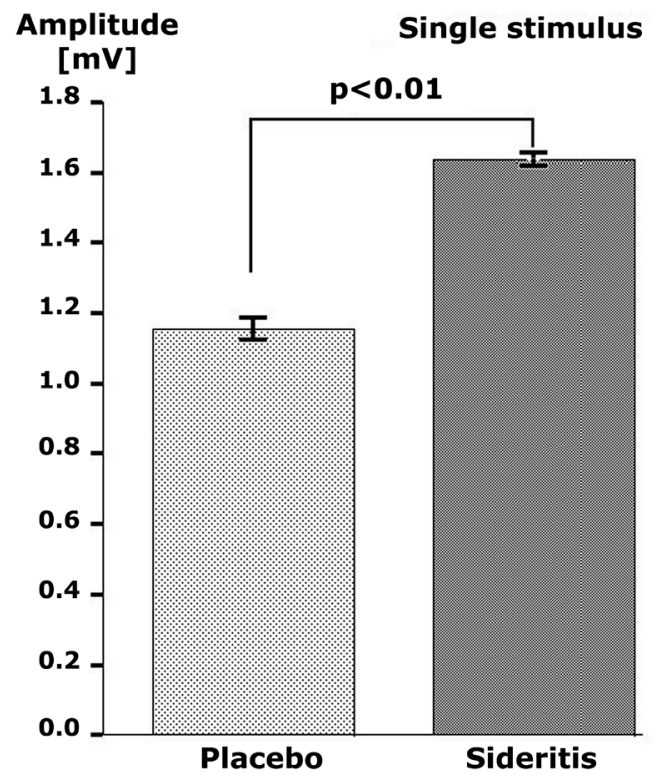

Figure 4. Effect of Sideritis scardica extract on population spike amplitude in the presence of single stimuli in comparison to placebo after one week of repetitive dosing. Data are given from 8 slices from 2 rats (given as $\mathrm{mV}$ on the ordinate).

similar way as described in the first part of the study. After having proof of this action it was justified to test, if one of 6 glutamatergic receptor antagonists was able to reverse this Sideritis modulates hippocampal excitability by perfusing the slice with it in the submersion chamber. Now, 6 antagonists of different glutamate receptors were tried in the presence of single or theta burst stimuli in order to find out if one or more of them were able to reverse or block the effects of the Sideritis extract.

Four slices from one rat were exposed to each of the antagonists. Out of the six antagonists only the antagonist interacting with the AMPA receptor modulated the amplitude of the populations spike during single stimuli as well as during theta burst stimulation. The rather specific AMPA receptor antagonist NBQX at a concentration of $0.05 \mu \mathrm{M}$ clearly depressed the enhanced amplitude of the population spike induced by Sideritis scardica extract completely in a highly statistically significant manner. This result is documented in Figure 5. All other antagonists produced negative results. Neither the NMDA receptor antagonist CGS 19755 nor the Kainate receptor antagonist UB 301 were able to influence the positive modulation by Sideritis extract. Furthermore, also the metabolic glutamatergic antagonists YM 298198, (RS)-APICAand MSOP standing for interaction with the metabotropic glutamatergicmGluI, mGlu II and mGlu III receptor, respectively, were not able to reverse the action of Sideritis scardicaextract. Overview on the results is given in Figure 6.

\section{Discussion}

The hippocampus is known for its involvement in cognitive actions, especially with 


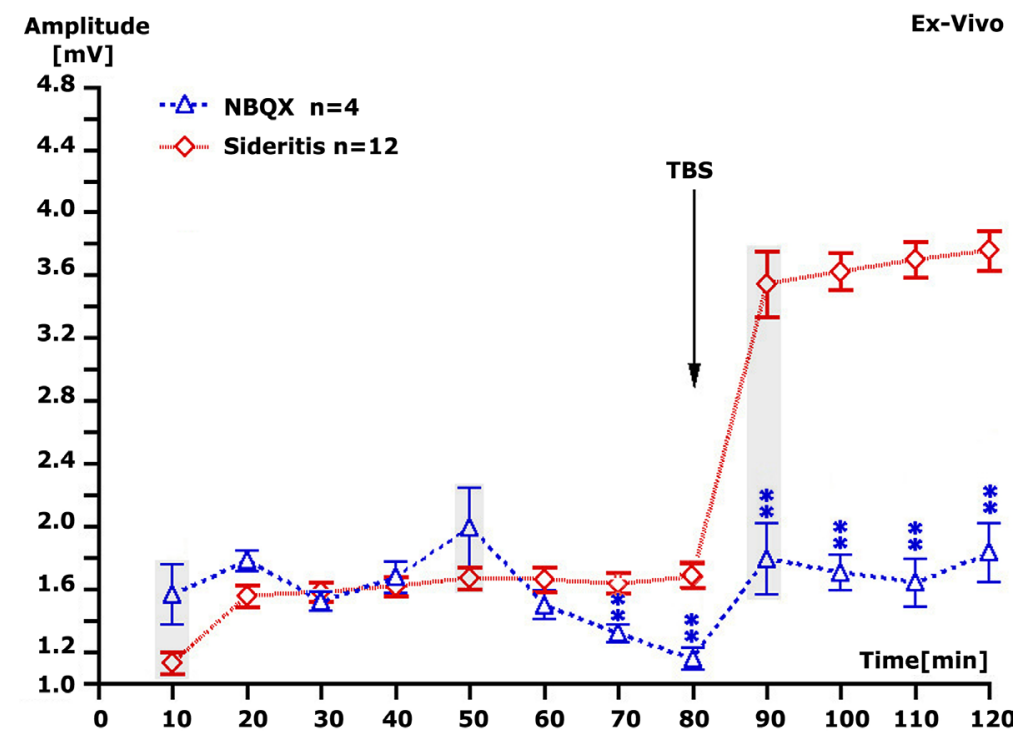

Figure 5. Effect of $0.05 \mu \mathrm{M}$ of NBQX, a glutamatergic AMPA receptor antagonist, on the hippocampus in vitro of a rat treated with Sideritis scardicaextract for one week. Results as obtained after single stimuli (10 - $80 \mathrm{~min}$ ) or after burst stimuli (90 - $120 \mathrm{~min}$ ) (given as $\mathrm{mV}$ on the ordinate). The shadowed areas are transitional data, which are not used for average values. Statistics Wilcoxon u-test Mann und Whitney ${ }^{*} \mathrm{p}<0.05$; ${ }^{* *} \mathrm{p}<0.01$.

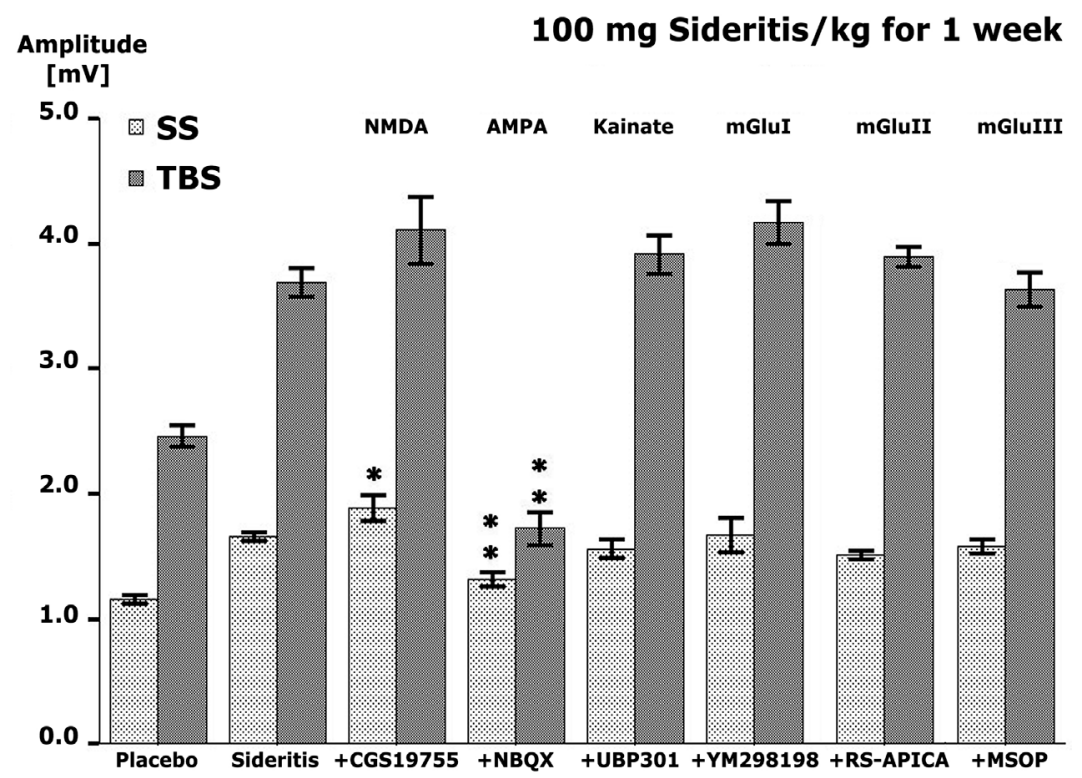

Figure 6. Overview on possible interference between the action of sideritis and different glutamatergic antagonists in the presence of theta burst stimulation after one week of repetitive dosing with placebo or sideritis scardica extract (given as $\mathrm{mV}$ on the ordinate). Data are documented as average of $n=4$ slices.

respect to space and time dependent memory [7]. In more than 1000 publications long term potentiation (LTP) has been related to these features. In the past, it has been 
shown that antidementive drugs like memantine and tacrine were able to increase the population spike amplitude during single stimuli and theta burst stimulation leading to LTP. In terms of plant-derived preparations this was also shown for a Ginkgo bilobaextract Ph. Eur. quality (to be published). Results of Ginkgo extract using the hippocampus slice preparation have shown that the effect was antagonized by CGS19755, NBQX, YM298198 and (RS)-Apica (to be published). Thus, Ginkgo extract induced a much more unspecific effect based on NMDA, AMPA, metabotropic mGluI and II glutamate receptor-mediated electric transmission. Epigenetic effects of Ginkgo administration with respect to the AMPA receptor [8] may very well represent one of the mechanisms of its action. On the other side, 6-hydroxykynurenic acid, one of the possible active ingredients of Ginkgo, developed an antagonistic action on AMPA-mediated channel activity using a patch clamp design in the hippocampus in vitro [9]. So for Ginkgo extracts $\mathrm{Ph}$. Eur quality with an established use for cognitive improvement the AMPA influence can be seen only as one possible mode of action.

The present investigation dealt with the effects of Sideritis scardica extract. Daily repetitive administration succeeded in a clearly higher excitability of hippocampal pyramidal cells after single stimuli and theta burst stimulation. This implicates that Sideritis scardica extract might be able to improve cognitive functions. At some matter of fact exactly this has been shown in a human clinical study already after a single intake of $500 \mathrm{mg}$ of identical Sideritis scardica extract [10].

The result of this experimental approach opened the possibility to uncover the potential mode of action of Sideritis scardica extract by trying to antagonize its action by well-known receptor antagonists within the glutamatergic transmitter system as successfully shown for memantine and Ginkgo extract Ph. Eur. quality. The fact that only NBQX, a chemical interfering with the glutamatergic AMPA receptor activity, was able to reverse and block the positively modulated excitability of hippocampal pyramidal cells by Sideritis scardica extract points to a similar mechanism of action as proven for memantine 20 years ago [11]. AMPA receptors are glutamate-gated cation channels that mediate the overwhelming majority of fast excitatory transmission in the mammalian central nervous system and are involved in synaptic plasticity and age related cognitive decline by highly controlled trafficking and recycling [12]. Increases of AMPA receptors that contain GluA1, GluA3 and GluA4 subunits may help in maintaining cognition in pre-symptomatic 3xTG-AD mice [13]. It was shown recently, that the surface expression of Glutamate AMPA receptor in the hippocampus of aged rats that are cognitively impaired was much lower than that of young rats and aged rats with preserved cognitive abilities [14]. Interestingly, the AMPA receptor activation seems to be involved also in promoting drug induced antidepressant effects [15]. In general, there is a trend to develop AMPA receptor potentiators (allosteric modulators) for treatment of cognitive impairment and neurodegeneration [16]. From all this knowledge about AMPA receptors is can be concluded that Sideritis scardica extract is able to improve cognition and mental work as well as prevent age-dependent decline of mental fitness. A recent clinical study performed in mildly cognitively impaired subjects over 4 weeks 
revealed a positive effect by treatment with a mixture of Sideritis scadica extract with Bacopa extract [17]. In addition to antidementive treatment also at least an add-on treatment during ischaemic stroke might be considered [18].

\section{Acknowledgements}

We greatly appreciate the quality control and proof reading by Ingrid K. KeplingerDimpfel.

\section{References}

[1] Lynch, G. and Schubert, P. (1980) The Use of In-Vitro Brain Slices for Multidisciplnary Studies of Synaptic Function. Annual Review of Neuroscience, 3, 1-22.

http://dx.doi.org/10.1146/annurev.ne.03.030180.000245

[2] Dimpfel, W., Hoffmann, J.A. (2011) Effects of Rasagiline, Its Metabolite Aminoindan and Selegiline on Glutamate Receptor Mediated Signaling in the Rat Hippocampus Slice in Vitro. BMC Pharmacology, 11, 2. http://dx.doi.org/10.1186/1471-2210-11-2

[3] Dimpfel, W., Dalhoff, B., Hofmann, W. and Schlüter, G. (1994) Electrically Evoked Potentials in the Rat Hippocampus Slice in the Presence of Aminophylline Alone and in Combination with Quinolones. European Neuropsychopharmacology, 4, 151-156.

http://dx.doi.org/10.1016/0924-977X(94)90009-4

[4] Dimpfel, W., Spüler, M., Dalhoff, A., Hoffmann, W. and Schlüter, G. (1991) Hippocampal Activity in the Presence of Quinolones and Fenbufen in-Vitro. Antimicrobial Agents and Chemotherapy, 6, 1142-1146. http://dx.doi.org/10.1128/AAC.35.6.1142

[5] Haas, H.L., Schaerer, B. and Vosmansky, M. (1979) A Simple Perfusion Chamber for the Study of Nervous Tissue Slices in Vitro. Journal of Neuroscience Methodss, 1, 323-325. http://dx.doi.org/10.1016/0165-0270(79)90021-9

[6] Schiff, S.J. And Somjen, G.G. (1985) The Effects of Temperature on Synaptic Transmission in Hippocampal Tissue Slices. Brain Research, 345, 279-284.

http://dx.doi.org/10.1016/0006-8993(85)91004-2

[7] Bliss, T.V. And Collingridge, G.L. (1993) A Snaptic Model of Memory: Long-Term Potentiation in the Hippocampus. Nature, 361, 31-39. http://dx.doi.org/10.1038/361031a0

[8] Watanabe, C.M.H.,Wolffram, S., Ader, P., Rimbach, G., Packer, L., Maguire, J.J., Schultz, P.G. and Gohil, K. (2001) The in Vivo Neuromodulatory Effects of The herbal Medicine Ginkgo Biloba. PNAS, 98, 6577-6580.

[9] Weber, M., Dietrich, G., Gräsel, I., Reuter, G., Seifert, G. and Sreinhäuser, C. (2001) 6-Hydroxykynorenic Acid and Kynurenic Acid Differently Antagonise AMPA and NMDA Receptors in Hippocampal Neurones. Journal of Neurochemistry, 77, 1108-1115. http://dx.doi.org/10.1046/j.1471-4159.2001.00340.x

[10] Dimpfel, W., Biller, A., Suliman, S. and Dipah, G. (2016) Psychophysiological Effects of a Combination of Sideritis and Bacopa Extract (memoLoges ${ }^{\circledast}$ ) in 32 Subjects Suffering from Mild Cognitive Impairment: A Double-Blind, Randomized, Placebo-Controlled, 2-Armed Study with Parallel Design. (To be published)

[11] Dimpfel, W. (1995) Effects of Memantine on Synaptic Transmission in the Hippocampus in Vitro. Arzneimittel Forschung-Drug Research, 45, 1-5.

[12] Henley, M. (2013) AMPA Receptor Trafficking and the Mechanisms Underlying Synaptic Plasticity and Cognitive Aging. Dialogues in Clinical Neuroscience, 15, 11-27. 
[13] Cantanelli, P., Sperduti, S., Ciavardelli, E., Stuppia, L., Gatta, V. and Sensi, S.L. (2014) Age-Dependent Modifications of AMPA Receptor Subunit Expression Levels and Related Cognitive Effects in 3xTg-AD Mice. Frontiers in Aging Neuroscience, 6, 1-11. http://dx.doi.org/10.3389/fnagi.2014.00200

[14] Yang, Y.J., Chen, H.B., Wei, B., Wang, W., Zhou, P.L., Zhan, J.Q., Hu, M.R., Yan, K., Hu, B. and $\mathrm{Yu}, \mathrm{B}$. (2015) Cognitive Decline Is Associated with Reduced Surface GluR1 Expression in the Hippocampus of Aged Rats. Neuroscience Letters, 591, 176-181.

http://dx.doi.org/10.1016/j.neulet.2015.02.030

[15] Andreasen, J.T., Fitzpatrick, C.M., Larsen, M., Skovgaard, L., Nielsen, S.D., Clausen, R.P., Troelsen, K. and Pickering, D.S. (2015) Differential Role of AMPA Receptors in Mouse Tests of Antidepressant and Anxiolytic Action. Brain Research, 1601, 117-126. http://dx.doi.org/10.1016/j.brainres.2015.01.001

[16] Partin, K.M. (2015) AMPA Receptor Potentiators: From Drug Design to Cognitive Enhancement. Current Opinion in Pharmacology, 20, 46-53.

http://dx.doi.org/10.1016/j.coph.2014.11.002

[17] Dimpfel, W., Biller, A., Suliman, S. and ChiegouaDipah, G.N. (2016) Psychophysiological Effects of a Combination of Sideritis and Bacopa Extract (memoLoges ${ }^{\circledast}$ ) in 32 Subjects Suffering from Mild Cognitive Impairment. A Double-Blind, Randomized, PlaceboControlled, 2-Armed Study with Parallel Design. Advancesin Alzheimer's Disease, 5, 103 125. http://dx.doi.org/10.4236/aad.2016.53008

[18] Atkins, P.T. and Atkinson, R.P. (2002) Glutamate AMPA Receptor Antagonist Treatment for Ischaemic Stroke. Current Medical Research and Opinion, 18, 9-13.

http://dx.doi.org/10.1185/030079902125000660

\section{Submit or recommend next manuscript to SCIRP and we will provide best service for you:}

Accepting pre-submission inquiries through Email, Facebook, LinkedIn, Twitter, etc.

A wide selection of journals (inclusive of 9 subjects, more than 200 journals)

Providing 24-hour high-quality service

User-friendly online submission system

Fair and swift peer-review system

Efficient typesetting and proofreading procedure

Display of the result of downloads and visits, as well as the number of cited articles

Maximum dissemination of your research work

Submit your manuscript at: http://papersubmission.scirp.org/

Or contact pp@scirp.org 